\title{
Effect of prolonged feeding of differently saturated fats to laying hens on performance, blood pressure, plasma lipids and changes in the aorta*
}

\author{
By HANS FISHER, H. S. WEISS, G. A. LEVEILLE, A. S. FEIGENBAUM, \\ S. HURWITZ, O. DONIS AND H. LUTZ \\ Department of Poultry Science, Rutgers, The State University, \\ New Brunswick, New fersey
}

(Received 27 November 1959-Revised 9 May 1960)

Many reports have appeared in the last few years on the influence of dietary fat on cholesterol metabolism. Short-term studies by Ahrens, Blankenhorn \& Tsaltas (1954); by Ahrens, Insull, Blomstand, Hirsch, Tsaltas \& Peterson (1957) and by Beveridge, Connell \& Mayer (1956) and others have indicated a relationship in human subjects between the relative percentage intake of saturated and unsaturated fats and the blood cholesterol level and, by inference, atherogenesis. Similarly in the chicken, a species well suited for studies on atherosclerosis (Katz \& Stamler, 1953), the type of dietary fat has also been shown to influence the blood lipids as well as the severity of atherosclerosis (Fisher, Feigenbaum, Leveille, Weiss \& Griminger, 1959; Leveille, Feigenbaum \& Fisher, 1959).

Although it is generally recognized that atherosclerosis is more likely to affect people as well as chickens in more advanced age groups, few nutritional studies have been carried out either in older chickens or over a prolonged time span (Buddecke, 1958; Fisher et al. 1959). Two recent reports from our laboratories provide: (I) for the first time a series of values on atherosclerosis in the chicken collected from a genetically similar group of animals ranging up to 5 years of age and maintained continuously on a hen ration of standard known composition (Weiss, 1959); and (2) additional biochemical information from three different age groups of chickens that had been on controlled and well-defined diets for a I-year experimental period (Fisher et al. 1959). The purpose of this report is to extend the previous observations to a single group of hens subdivided to receive either no supplementary fat or $10 \%$ of animal fat or maize oil over a 3-year experimental period.

Theoretical considerations underlying the measurement of the various blood and aortic lipids and of the aortic hydroxyproline content have been previously discussed (Fisher et al. 1959; Weiss \& Fisher, 1959). In this study, besides the above-mentioned measurements, blood pressure was included, since haemodynamic factors are generally believed to be involved in arteriosclerosis (Blumenthal, 1956) and have been considered of some importance in the avian disease (Weiss \& Fisher, 1959).

* Paper of the Journal Series, New Jersey Agricultural Experiment Station. Supported in part by grants-in-aid from U.S. Public Health Service, N.J. Heart Association, Central Jersey Farmers Cooperative Association, Hightstown, N.J. 


\section{EXPERIMENTAL}

Single Comb White Leghorn pullets were used in this study. They were raised on a maize-soya-bean ration unsupplemented with fat, until I2 weeks of age, at which time they were divided into three groups of twenty-four and placed on either $(a)$ a similar unsupplemented ration, $(b)$ a similar ration with $10 \%$ added maize oil, or $(c)$ a similar ration with $10 \%$ added animal fat (yellow grease, see Table $\mathrm{I}$ ). During the ist year each of the three treatments was further subdivided into treatments at two different protein levels. It was considered possible that egg production on a standard $16 \%$ protein ration might be adversely affected upon the addition of $10 \%$ fat because of decreased food consumption due to an increased calorie value of the ration.

The Ist year results, which have been previously presented (Leveille \& Fisher, 1958 ), indicated no significant difference in production performance between the two protein levels. Therefore, during the 2 nd and $3^{\text {rd }}$ years each treatment was continued at only one protein level $(16 \%)$. It was further deemed important to have a larger number of animals for each treatment, particularly for the final estimation of atherosclerotic changes. Since four birds died during the ist year on the diet with animal fat, all groups were equalized, so that at the beginning of the 2nd year of egg production twenty hens were available in each of the groups.

The birds were housed in individual cages in a temperature-regulated room $\left(65-70^{\circ} \mathrm{F}\right)$. Food was supplied from community feeders to groups of five birds, so that each treatment, in terms of feeders, was subdivided into four replicates. Separate egg records were kept daily for each hen, but food consumption was recorded on a monthly basis for all birds on each dietary regime. No effort was made to force all birds to moult at any one time throughout the 3-year experimental period, and no generalized moult affecting more than two or three birds simultaneously was ever recorded. Feed and water were supplied $a d$ lib. As previously stated, six diets were given during the Ist year and three diets (diets 1,2 and 3 ) until the end of the experiment. The composition of the rations is listed in Table $\mathrm{I}$.

For measurements of plasma cholesterol blood was drawn from a wing vein and centrifuged. Determinations by the method of Zlatkis as modified by Griminger \& Fisher (1958) were done at 4- to 6-week intervals during the Ist year, but only at 3 -month intervals during the 2 nd and $3^{\text {rd }}$ years of the study.

Iodine values of the plasma fat were determined on a different portion of the same blood sample as was used for the cholesterol determination, by the method of Luddy, Barford, Riemenschneider \& Evans (1958). At infrequent intervals throughout the study iodine values were also determined by the conventional Wij's method (Association of Official Agricultural Chemists, 1955) on chloroform-methanol (2:1) extracts of pooled yolks from eggs laid by hens from each treatment group.

Systolic blood pressure was measured indirectly on unanaesthetized birds by means of a I in. wide pneumatic leg cuff (Weiss \& Sturkie, 195I; Sturkie, Durfee \& Sheahan, 1957) with a capacitance pulse pick-up and pulse monitor (manufactured by Biophysical Electronics Inc., 400 Northern Boulevard, Great Neck, New York) to indicate end-points. 
At the end of the experiment plasma poly-unsaturated fatty acids were determined by the alkali-isomerization method of Morris, Riemenschneider \& Evans (1958). After the birds had been killed, the aortas were removed from the heart to the iliac bifurcation, thoroughly cleaned and visually scored by one of us (H. S. W.) as

\section{Table I. Percentage composition of experimental diets}

\begin{tabular}{|c|c|c|c|c|c|c|}
\hline Ingredient & Lot I & Lot 2 & Lot 3 & Lot 4 & Lot 5 & Lot 6 \\
\hline Yellow-maize meal & 62 & 52 & 52 & 42 & 32 & 32 \\
\hline Soya-bean meal ( $50 \%$ protein) & 20 & 20 & 20 & 40 & 40 & 40 \\
\hline Maize oil** & - & - & 10 & - & - & Io \\
\hline Animal fat $\dagger$ & - & 10 & - & - & Io & - \\
\hline Basal diet $f$ & I 8 & 18 & 18 & I 8 & 18 & 18 \\
\hline \multicolumn{7}{|l|}{ Calculated composition } \\
\hline Protein $(N \times 6.25)$ & 17 & I6 & 16 & 26 & 25 & 25 \\
\hline Calcium & $2 \cdot 68$ & $2 \cdot 68$ & $2 \cdot 68$ & $2 \cdot 75$ & $2 \cdot 75$ & $2 \cdot 75$ \\
\hline Phosphorus & $I \cdot I 6$ & $I \cdot I 3$ & $I \cdot I 3$ & 1.25 & $1 \cdot 23$ & $1 \cdot 23$ \\
\hline $\begin{array}{l}\text { Metabolizable energy } \\
(\mathrm{kcal} / \mathrm{lb})\end{array}$ & 1242 & I420 & 1480 & II 63 & 1342 & 1410 \\
\hline Calories supplied by fat (\%) & - & 23 & 27 & - & 24 & 28 \\
\hline
\end{tabular}

* Edible maize oil, Staley Manufacturing Company, Decatur, Illinois.

+ Yellow grease, with the following specifications of the Fat Analysis Committee of the American Oil Chemists' Society (1957-8): (FAC) colour, 37-39; free fatty acids (FFA), 15-20\%; moisture and unsaponifiable material (MIU), maximum $2 \cdot 0$; activated oxygen method (AOM) value, not less than $20 \mathrm{~h}$.

$\ddagger$ The basal diet was composed of (values are expressed as percentages of the complete diet): dehydrated alfalfa 3 , dried whey 2 , maize distiller's solubles 2 , butyl fermentation solubles 2 , dicalcium phosphate 4, limestone I, trace mineral mix 3 (Mico concentrate, Limestone Corporation of America, Newton, New Jersey), salt 0.5 , choline chloride ( $70 \%$ concentration) 0.05 , vitamins $A$ and $\mathbf{D}$ premix 0.22 (furnished 6600 i.u. vitamin $A$ and I 190 i.u. cholecalciferol/lb diet), cyanocobalamin and antibiotic supplement $0 \cdot 5$, DL-methionine $0 \cdot 1$.

previously described (Weiss, 1959). The thoracic and abdominal segments were scored separately on a $\mathrm{I} \cdot 0-6 \cdot 0$ scale. The scoring system used gives greatest emphasis to the degree of lumen encroachment by proliferative lesions and secondarily evaluates gross lipaemia, hardness and roughness of the intimal surface. After scoring, each aorta was separated into a thoracic and an abdominal segment, and these were separately extracted in a shaker for $24 \mathrm{~h}$ with chloroform-methanol 2: $\mathrm{I}$. Portions of the extract were used for the determination of cholesterol, of iodine values and of polyunsaturated fatty acids (Herb \& Riemenschneider, I953). The aortic residues were dried, weighed and hydrolysed with $6 \mathrm{~N}-\mathrm{HCl}$ at $15 \mathrm{lb}$ pressure for $24 \mathrm{~h}$. Hydroxyproline was determined in the hydrolysate, as a measure of collagen content, by the method of Neuman \& Logan (1950).

\section{RESULTS AND DISCUSSION}

Performance of hens. Table 2 gives the pertinent results, averaged for each group on a yearly basis. Mortality tended to be greater in the group given animal fat, confirming previous findings (Weiss \& Fisher, 1957; Donaldson \& Millar, 1958). No specific common cause of death could be established for the birds that died during this study. The birds receiving animal fat were also on the average slightly heavier, particularly in the rst year on experiment. As expected, the groups given maize oil or animal fat 
were more efficient in their food utilization than those fed on the unsupplemented diet, undoubtedly a reflexion of the differences in calorie values between the three diets. The iodine values of the egg fat, in line with earlier observations (Fisher \& Leveille, 1957), were the same for the hens receiving the unsupplemented diet and the diet with animal fat and lower than those for the hens given maize oil.

Table 2. Performance of hens receiving for 3 years a diet with no fat supplement or with $10 \%$ of animal fat or maize oil

\begin{tabular}{|c|c|c|c|c|c|}
\hline Period & $\begin{array}{l}\text { Mortality } \\
\text { (no.)* }\end{array}$ & $\begin{array}{c}\text { Body-weight } \uparrow \\
(\mathrm{kg})\end{array}$ & $\begin{array}{c}\text { Egg } \\
\text { production } \dagger \ddagger \\
(\%)\end{array}$ & $\begin{array}{c}\text { Food } \\
\text { utilization } \\
\text { (kg food } \\
\text { eaten/dozen } \\
\text { eggs laid) }\end{array}$ & $\begin{array}{l}\text { Iodine } \\
\text { value of } \\
\text { egg fat }\end{array}$ \\
\hline \multicolumn{6}{|c|}{ No supplement } \\
\hline Ist year & I & $1.93 \pm 0.02$ & $67 \cdot 7 \pm 4 \cdot 9$ & $2 \cdot 2$ & 70 \\
\hline 2nd year & 0 & $2 \cdot 13 \pm 0.05$ & $44 \cdot 5 \pm 3 \cdot 2$ & $3 \cdot I$ & - \\
\hline $3^{\text {rd }}$ year & 2 & $2.32 \pm 0.02$ & $26 \cdot I \pm 2 \cdot 0$ & $4 \cdot 6$ & 63 \\
\hline \multicolumn{6}{|c|}{ Maize-oil supplement } \\
\hline Ist year & $\mathrm{r}$ & $1 \cdot 95 \pm 0.03$ & $63.7 \pm 4.4$ & $1 \cdot 9$ & 81 \\
\hline 2nd year & 3 & $2.02 \pm 0.04$ & $43^{\circ} 4 \pm 2 \cdot 7$ & $2 \cdot 6$ & - \\
\hline $3^{\text {rd }}$ year & I & $2.30 \pm 0.05$ & $23 \cdot 2 \pm 2 \cdot 0$ & $4 \cdot 2$ & 84 \\
\hline \multicolumn{6}{|c|}{ Animal-fat supplement } \\
\hline ist year & 4 & $2 \cdot 04 \pm 0.03$ & $65 \cdot 7 \pm 4 \cdot 9$ & $2 \cdot 0$ & 68 \\
\hline 2nd year & I & $2 \cdot 06 \pm 0.07$ & $40 \cdot 9 \pm 2 \cdot 3$ & $2 \cdot 8$ & - \\
\hline $3^{\text {rd year }}$ & 4 & $2.37 \pm 0.03$ & $26 \cdot 0 \pm 2 \cdot 2$ & $4 \cdot 1$ & 67 \\
\hline
\end{tabular}

* Twenty-four birds were originally put on each treatment; at the end of the ist year four birds had died on the animal-fat ration, and all groups were equalized to twenty per treatment for consideration of space.

$\dagger$ Mean value with its standard error.

$\ddagger$ Calculated on a hen-day basis.

Comparison of egg-production (given in percentage on a hen-day basis, Table 2) shows little difference between the three treatment groups during any of the three production years, although there is a slight trend indicating better production on the unsupplemented diet when compared to either fat group.

Because of the close agreement between groups, the production records were pooled and the best-fitting regression line was calculated by the method of least squares. This fit was obtained with the linear expression, the quadratic term not being significant. Fig. I shows the linear decline in egg production for the pooled production records of all groups for $3^{1}$ months during this study. This linear decline indicates that the drop in production was probably not synonymous with true ageing (senescence) as defined by Comfort (1956), whose typical senescence curve shows first a relatively constant plateau and then a precipitous drop. Under normal environmental housing conditions, each of the production years would have been followed by a moult and a new production peak at the end of the moulting period. These changes were completely absent when the birds were maintained under constant controlled temperature conditions without a forced moult. 
Blood pressure. Various fat supplements given to the chicken over 3 years in no way affected final systolic blood pressure (Table 3), which makes it highly unlikely that haemodynamic factors would be involved in any difference in the incidence or severity of atherosclerosis among the three groups. Values for all groups in the present study were higher than previously reported for birds of similar age groups (Weiss \& Fisher, I959; Sturkie, Weiss \& Ringer, 1953). In the earlier studies, however, the birds had been housed on the floor, whereas in this study they were maintained in cages, which severely restricted the amount of movement and exercise. Since the body-weights of

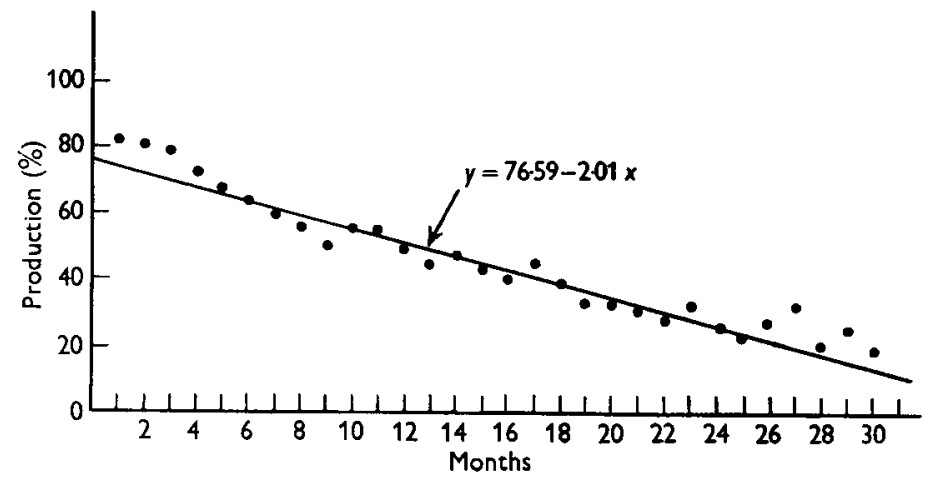

Fig. I. Decline of egg production by hens in a temperatureregulated room over $3 \mathrm{I}$ months.

Table 3. Mean values with their standard errors for plasma cholesterol and blood pressure of hens receiving for 3 years a diet with no fat supplement or with $10 \%$ of animal fat or maize oil

\begin{tabular}{|c|c|c|c|}
\hline $\begin{array}{c}\text { Fat } \\
\text { supplement }\end{array}$ & $\begin{array}{c}\text { Year on } \\
\text { experiment }\end{array}$ & $\begin{array}{c}\text { Plasma } \\
\text { cholesterol } \\
(\mathrm{mg} / \mathrm{L} 00 \mathrm{ml})\end{array}$ & $\begin{array}{c}\text { Systolic blood } \\
\text { pressure } \\
\text { (mm Hg) }\end{array}$ \\
\hline None & $\begin{array}{l}\text { Ist } \\
\text { and }\end{array}$ & $\begin{array}{l}199 \pm 13 \\
221 \pm 10\end{array}$ & \\
\hline & $3 \mathrm{rd}$ & $231 \pm 13$ & $176 \pm 6$ \\
\hline Mean & & 217 & \\
\hline Maize oil & $\begin{array}{l}\text { Ist } \\
\text { 2nd } \\
3 \text { rd }\end{array}$ & $\begin{array}{l}204 \pm I 4 \\
23 I \pm I 7 \\
252 \pm I 2\end{array}$ & $183 \pm 6$ \\
\hline Mean & & 229 & \\
\hline Animal fat & $\begin{array}{l}\text { Ist } \\
\text { 2nd } \\
\text { 3rd }\end{array}$ & $\begin{array}{l}221 \pm 16 \\
251 \pm 30 \\
246 \pm 20\end{array}$ & $175 \pm 4$ \\
\hline Mean & & 239 & \\
\hline
\end{tabular}

all hens in this study were also greater (Table 2) than those of birds of similar age maintained in floor pens, differences in both blood pressure and body-weight might well be explained by the decreased activity of the caged birds.

Plasma cholesterol. The plasma-cholesterol values shown in Table 3 indicate a small increase in concentration with advancing age. Previous results had suggested 
no change in hens up to 5 years of age (Weiss, I957); moreover, the cholesterol levels found by us were considerably higher than those found previously in floor-housed birds. Since exercise has been shown to affect the plasma-cholesterol level of the chicken (Warnock, Clarkson \& Stevenson, 1957; Orma, 1957), the difference between the results of this study and those of former ones can probably again be explained by the different levels of physical activity.

In line with previous observations during short-term feeding trials (Weiss \& Fisher, I957; Fisher et al. 1959), the blood-cholesterol levels in the group given animal fat appeared higher (though not significantly so) than those for the unsupplemented group or the group given maize oil. During the $3^{\text {rd }}$ year the earlier differences disappeared completely. This observation supports the necessity for long-term studies to evaluate the true effect of dietary manipulation on blood lipid metabolism and its relationship to arteriosclerosis.

We would call attention to the plasma-cholesterol levels of the hens that died, recorded at the last sampling period before death. In the unsupplemented group one out of the three hens that died during the course of the studies showed an elevated cholesterol level before death, compared with the other birds on the same diet at the same sampling period (37 I against $202 \mathrm{mg} / \mathrm{I} 00 \mathrm{ml}$ ). In the group given maize oil none of the five birds that died had a plasma-cholesterol level substantially higher than those of the survivors (27 $\mathrm{I}$ as against $238 \mathrm{mg} / \mathrm{ro0} \mathrm{ml}$ ). Of the nine birds that died on the animal-fat diet, however, six showed decidedly elevated cholesterol concentrations compared with those of the survivors (555 as against $243 \mathrm{mg} / 100 \mathrm{ml}$ ). This finding suggests that higher cholesterol levels may have contributed to a derangement in lipid metabolism and to the deaths of the animals.

Aortic cholesterol. Cholesterol concentrations were higher in the abdominal than in the thoracic portion of the aorta. For the three treatment groups the thoracic segments showed small differences (Table 4), but highly significant differences were evident in the abdominal segments. The unsupplemented group had the lowest and the group supplemented with animal fat the highest cholesterol concentration. Though a parallel trend was evident for the aorta cholesterol and the mean 3 -year value for plasma cholesterol, the correlations between aortic and plasma cholesterol, whether for the 3-year mean or the ist or 2nd year plasma values, were not significant (Table 5). These results indicate that the deposition of cholesterol in the aorta was not a simple reflection of the level of circulating cholesterol. On the other hand, the positive and significant correlation between abdominal aortic cholesterol and systolic pressure (Table 5) suggested that haemodynamic factors may have contributed to the cholesterol deposition.

Aortic hydroxyproline. Higher hydroxyproline concentrations were present in the abdominal than in the thoracic segment of the aorta, but there were no differences among the three treatment groups (Table 4 ). This result suggests that dietary treatment had no influence on the concentration of collagen in the tissues, but does not automatically eliminate the possibility of effects on tissue proliferations. Thus, although the importance of fibrotic proliferations in atherogenesis is well established, the hydroxyproline content of an entire aortic segment would not necessarily 


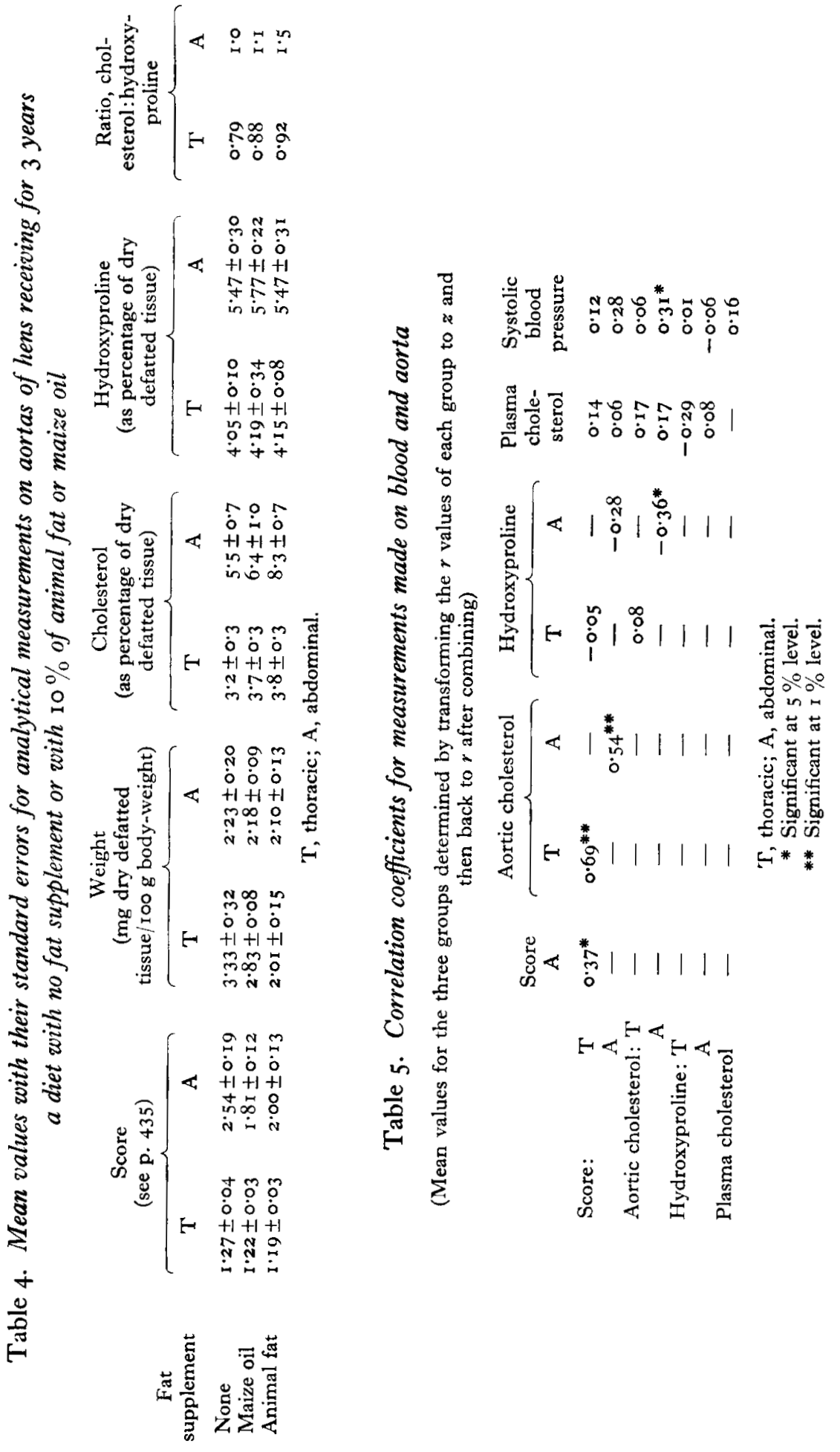


differentiate between vessels with varying degrees of proliferative lesions if the plaques and unaffected area contained the same proportion of collagen.

Aortic hydroxyproline concentration was not correlated with systolic blood pressure on an individual-bird basis (Table 5). Weiss \& Fisher (1959) had previously shown that a relationship existed between blood pressure and aortic hydroxyproline concentration when the comparison was among groups of males, females, capons and poulards. The significant negative correlation between hydroxyproline and cholesterol concentration in the abdominal segment (Table 5) suggests that the lipid deposited in the aorta could have inhibited collagenous proliferation.

When we compare the aortic cholesterol:hydroxyproline ratios found in this study (Table 4) with those reported by Weiss \& Fisher (1959), we find that values for both aortic segments then reported for hens agree well with our values for the unsupplemented group and the group given maize oil. The ratios for the group supplemented with animal fat do not agree, probably owing to their greatly elevated cholesterol concentrations.

Plasma fat. Despite small differences between iodine values of the plasma fat extracts (Table 6) from the three groups of hens, there were major changes in the fatty-acid components of these extracts. As expected, the dienoic-acid content of plasma from hens given maize oil was higher than for those in either of the other groups. After a diet rich in dienoic acid is given to hens, the increase in the dienoic acid of egg-yolk fat was previously shown to be at the expense of a decrease in monoenoic acid (Feigenbaum \& Fisher, 1959). In the plasma there appears to be an exchange of saturated fatty acids as well. This exchange between the dienoic and the saturated fatty acids is particularly apparent when the group given animal fat is compared with the unsupplemented group. We would point out the lack of relationship between the plasma cholesterol level and the poly-unsaturated fatty-acid content of the plasma.

Aortic fat. The abdominal segment of the aorta contained significantly more substances extractable with chloroform-methanol than did the thoracic segment (Table 6). The pattern of the poly-unsaturated fatty acids followed essentially that observed in the plasma of the group with animal fat, showing again a dienoic-acid level reduced below that of the unsupplemented group. Though the polyenoic acids appeared to be in close conformity with those in the plasma, the amount of saturated fatty acids was significantly greater in the aortic fat, primarily as a result of a decreased mono-enoic fatty-acid content.

Aortic score and general discussion. The severity of the aortic lesions based upon score was greatest on the unsupplemented or control diet and less on both of the fat treatments. The low score for the group given animal fat was completely unexpected and immediately raised some question as to the validity and interpretation of the score. Always with a subjective evaluation, such as the scoring used here, it is possible that some systematic error or bias has been introduced. In this instance the usual precautions were taken of having the aortas randomly graded by the same person without his knowing the group of origin.

It may be pointed out in defence of the subjective technique that the score for the 
Vol. I4

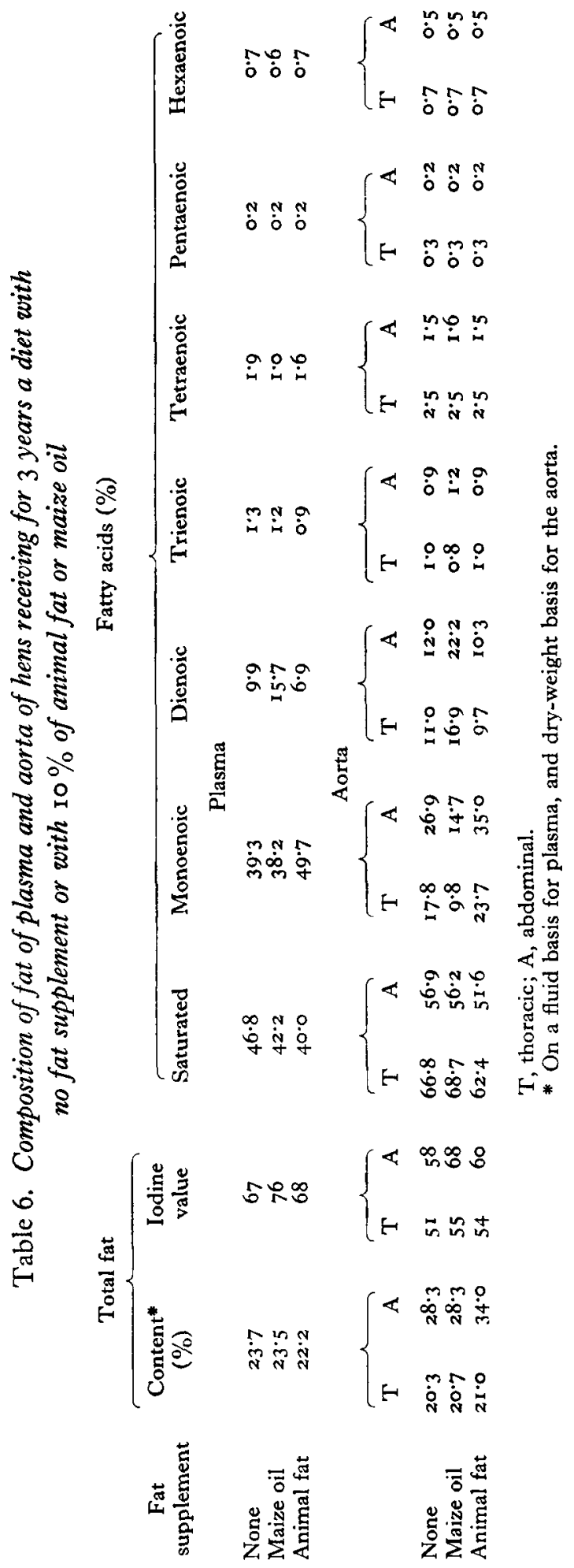


controls in this study agrees well with all previous work from these laboratories for hens of the same age on similar unsupplemented diets (Weiss, 1959; Weiss \& Fisher, 1959; Fisher et al. 1959). Also the higher scores of the abdominal segment compared with those of the thoracic segment were typically associated with the higher concentrations of cholesterol and hydroxyproline. Finally, it is only the scores of the tallow group that were unusual, for the relationship between the birds given maize oil and the controls in this study followed the pattern found previously between birds given another unsaturated fat, linseed oil, and the controls (Fisher et al. 1959).

The inter-group differences in visually estimated intimal proliferation were not supported by the aortic hydroxyproline values, which were unchanged among the groups, or the measurements of aortic cholesterol and fat, which were lowest for the controls. The amounts of both aortic hydroxyproline and cholesterol have been previously found to be correlated with group differences in scored atherosclerosis, although under different experimental conditions in which diet was not a variable (Weiss \& Fisher, 1959). In another previous study (Fisher et al. 1959) in which diet, and particularly dietary fat, were variables, no inter-group relationship between aortic cholesterol and score was evident. In our opinion, inter-group differences in aortic cholesterol are of little significance in defining the extent or severity of aortic lesions.

Among the within-group comparisons there was no correlation between score and hydroxyproline, but a significant correlation did exist between score and aortic cholesterol (Table 5). If it is assumed that the scores are reliable estimations of intimal proliferation, then the unrelated inter- and intra-group changes between aortic score and hydroxyproline suggest that in the evaluation of atherosclerosis of each aortic segment of the adult female: (I) the ratio of collagen to fat-free tissue was probably the same in the plaque areas as in the lesion-free areas; (2) despite the importance of collagen-containing fibrotic lesions in atherosclerosis, estimation of collagen in terms of hydroxyproline per unit aortic weight will not differentiate between lesions of varying severity. The fact that there was no clear relationship between score and aortic cholesterol among groups, but that a significant correlation existed within groups suggests for the adult hen: (I) plaques contain more cholesterol than normal aortic tissue, regardless of the over-all concentration of cholesterol in the aorta; (2) among differently fed groups, high aortic fat and cholesterol do not necessarily signify more severe intimal proliferative lesions.

Again, if it is assumed that the scores in both this and previous studies are reliable estimates of atherosclerosis, then the lower scores associated with supplements of linseed oil or maize oil provide the consistent interpretation that unsaturated fats inhibit the development of proliferative aortic lesions. Such a conclusion is implicit in the fact that the lowest scores occurred on a diet with $10 \%$ linseed oil given for I year to hens that were either 8 or 20 months old at the beginning (Fisher et al. 1959) and on a diet with $10 \%$ maize oil given for 3 years to birds 12 weeks old at the beginning of this study. It is further implicit in these results that the inhibition of fibrotic lesions may occur in the presence of higher than 'normal' plasma and aortic cholesterol levels.

There is no satisfactory explanation for the low scores associated with 3 years of 
feeding on saturated fat. Apparently the initial effect of the saturated-fat diet is to increase the severity of the aortic lesions (Weiss \& Fisher, 1957; Fisher et al. 1959); however, if such diets are continued long enough, the atherogenic process is not only slowed but may even be reversed. Though one may speculate that the diffuse deposits of lipid in the arterial wall could in time inhibit fibrotic proliferation, as they apparently did in the group given the unsaturated fat, and though there are some reports that even fibrotic lesions may regress under certain conditions (Weitzel \& Buddecke, I956), there is no evidence that such regression could be produced by prolonged feeding on a highly saturated animal fat.

Possibly a partial explanation for the low score of the saturated-fat group at the end of 3 years is the fact that mortality in this group was three times as high as in the unsupplemented group. If there should be any direct relationship between high score and early mortality, then proportionately more low-scoring birds should have survived the 3 years in the saturated-fat group than in the control. This hypothesis is considerably strengthened by the much higher plasma-cholesterol values of the birds that died in the group given animal fat compared with the survivors at the same sampling period. Moreover, these higher cholesterol concentrations were not evident in the birds that had died on the maize oil or the unsupplemented ration. Although the birds that died during this study were all autopsied in the State Diagnostic Pathology Laboratory, only non-specific causes of death could be established. The aortic scores for the birds that died are of no greater help in interpreting the results, because of the time intervals between deaths and the absence for comparison purposes of controls for the differences in age of the birds at time of death. It may be well to recognize that, despite the comparatively low score of the saturated-fat group at the end of 3 years, such indeterminate features as higher body-weight, higher mortality and higher aortic fat and cholesterol were more prominent in the saturated-fat group than in the group receiving the unsaturated fat.

\section{SUMMARY}

I. Three groups of pullets were given an unsupplemented diet or one supplemented with $10 \%$ of either maize oil or animal fat. The birds were placed on the experimental ration when 12 weeks old and continued on experiment for 3 years.

2. Egg production was similar and declined in a linear fashion with all treatments.

3. Of all the biochemical measurements made, only aortic-cholesterol concentration was significantly correlated with the observed visual atherosclerosis score within each treatment group; despite the within-group correlation, there was no correlation between score and cholesterol concentration on a between-group basis.

4. The abdominal region of the aorta, as in previous studies, was more severely affected with atherosclerotic lesions than the thoracic region, and it also showed heavier concentrations of total fat, cholesterol and hydroxyproline.

5. There were no differences in blood pressure between the three groups, which suggests that haemodynamic factors did not play an important role in the development of the observed lesions.

6. The hens fed on the ration supplemented with animal fat had a higher mortality 
and mean 3-year blood-cholesterol level, but less severe atherosclerotic involvement, than the birds on the unsupplemented diet. Although no good explanation for this finding is available, it is suggested that the threefold mortality of the group given animal fat compared with that of the unsupplemented group may provide a partial explanation.

7. The hens receiving maize oil had the lowest atherosclerotic scores, which were not, however, significantly different from those of the group given animal fat.

8. The importance of long-term nutritional studies is clearly indicated by the several differences between what we have observed and findings previously obtained in short-term studies and with younger animals.

The authors acknowledge with thanks receipt of certain materials from the following concerns: Monsanto Chemical Co., St Louis, Mo., and Stabilized Vitamins Inc., Garfield, N.J.

\section{REFERENCES}

Ahrens, E. H. Jr., Blankenhorn, D. H. \& Tsaltas, T. T. (1954). Proc. Soc. exp. Biol., N. Y., 86, 872. Ahrens, E. H. Jr., Insull, W. Jr., Blomstand, R., Hirsch, J., Tsaltas, T. T. \& Peterson, M. L. (1957). Lancet, 272, 943.

American Oil Chemists' Society (1957-8). Official and Tentative Methods of the American Oil Chemists' Society. Chicago, Ill.: American Oil Chemists' Society.

Association of Official Agricultural Chemists (1955). Official Methods of Analysis, 8th ed., p. 805. Washington, D.C.: Association of Official Agricultural Chemists.

Beveridge, J. M. R., Connell, W. F. \& Mayer, G. A. (1956). Canad. F. Biochem. Physiol. 34, 441.

Blumenthal, H. T. (1956). Geriatrics, Ir, 554 .

Buddecke, E. (r958). Z. physiol. Chem. 3ro, т82.

Comfort, A. (1956). The Biology of Senescence. New York: Rinehart and Company Inc.

Donaldson, W. E. \& Millar, R. I. (1958). Poult. Sci. 37, 1 r99.

Feigenbaum, A. S. \& Fisher, H. (1959). Arch. Biochem. Biophys. 79, 302.

Fisher, H., Feigenbaum, A., Leveille, G. A., Weiss, H. S. \& Griminger, P. (1959). F. Nutr. $69,163$. Fisher, H. \& Leveille, G. A. (1957). F. Nutr. 63, I I9.

Griminger, P. \& Fisher, H. (1958). Proc. Soc. Exp. Biol., N. Y., 99, 424.

Herb, S. F. \& Riemenschneider, R. W. (1953). Analyt. Chem. 25, 953.

Katz, L. N. \& Stamler, J. (1953). Experimental Atherosclerosis. Illinois: Charles C. Thomas.

Leveille, G. A., Feigenbaum, A. S. \& Fisher, H. (1959). Arch. Biochem. Biophys. 86, 67.

Leveille, G. A. \& Fisher, H. (1958). Poult. Sci. 37, 658.

Luddy, F. E., Barford, R. A., Riemenschneider, R. W. \& Evans, J. D. (1958). F. biol. Chem. $232,843$.

Morris, S. G., Riemenschneider, R. W. \& Evans, J. D. (1958). Arch. Biochem. Biophys. 78, I 38.

Neuman, R. E. \& Logan, M. A. (1950). F. biol. Chem. 184, 299.

Orma, E. J. (1957). Acta physiol. scand. 43, Suppl. 142.

Sturkie, P. D., Durfee, W. \& Sheahan, M. (1957). Poult. Sci. 36, I 16o.

Sturkie, P. D., Weiss, H. S. \& Ringer, R. K. (1953). Amer. F. Physiol. 174, 405.

Warnock, N. H., Clarkson, T. B. \& Stevenson, R. (1957). Circ. Res. 5, 478.

Weiss, H. S. (1957). Proc. Soc. Exp. Biol., N.Y., 95, 487.

Weiss, H. S. (1959). F. Geront. I4, 19.

Weiss, H. S. \& Fisher, H. (1957). F. Nutr. 6r, 267.

Weiss, H. S. \& Fisher, H. (1959). Amer. F. Physiol. 197, r2 19.

Weiss, H. S. \& Sturkie, P. D. (1951). Poult. Sci. 30, 587.

Weitzel, G. \& Buddecke, E. (1956). Klin. Wschr. 43, x 172. 